\title{
"We Clean Our Houses, Prepare for Weddings and Go to Funerals": Daily Lives of Elderly Africans in Majaneng, South Africa
}

\author{
Doris M. Bohman ${ }^{1,2}$, Sharon Vasuthevan ${ }^{3}$, Neltjie C. van Wyk ${ }^{3}$ and Sirkka-Liisa Ekman ${ }^{2}$ \\ (1) School of Health Science, Blekinge Institute of Technology, 37179 Karlskrona, Sweden \\ (2) Department of Neurobiology, Care Sciences and Society, Division of Nursing, Karolinska Institutet, Stockholm, Sweden \\ (3) Department of Nursing Science, University of Pretoria, Pretoria, South Africa
}

\begin{abstract}
This ethnographic study aims to identify and describe how a group of elderly African people in South Africa experience their daily life and related concerns and interests. Data were collected through group interviews involving 16 elderly persons and complementary field observations. The data were analysed using a qualitative content analysis. From the analysis following sub-themes emerged: 1 . Lack of basic resources; 2. Routines in daily life; 3. Experience of unsafe conditions; 4. "The disease"-HIVIAIDS. The results have been discussed according to the following themes: keeping normality and changing society. The study illuminates the varied experiences in daily life, including lack of basic resources, experience of unsafe conditions, and the HIVIAIDS pandemic and its consequences for the elderly as contributors to the extended family.
\end{abstract}

\section{Introduction}

Ageing is no longer an issue of concern to industrialized countries alone (United Nations Population Fund 2002). The health care of the elderly is becoming an urgent question for health care systems worldwide. By the year 2025 Africa is projected to have an elderly population of about 52.7 million, and even if Africa has not yet witnessed the full impact of the demographic transition, the continent is estimated to experience a large increase in the absolute number of persons aged 65 and over (US Census Bureau 2004).

In a developing country (OECD 2003) like South Africa the resources allocated to health care are insufficient (Flessa 2000), as many people have to rely on state-subsidized health care. Although classified as a lower middle-income country where $9.5 \%$ of total expenditure by the general government sector goes to health care (Statistics South Africa 2004), South Africa exhibits major disparities and inequalities. Under apartheid, Africans (black South Africans) were predominately located in "homelands" and in the "platteland." The apartheid policy affected the people of South Africa psychologically, as well as politically, socially, economically and medically. The degree of inequality and the extent of poverty were a consequence of deliberate policy (Wilson and Ramphele 1989).

The South African Older Persons Bill (Department of Social Development 2003) emphasizes improved services to older persons and the empowerment of the elderly population. The most important form of financial social support to elderly in South Africa, up till today, is the Old Age Grant, which is a rather unique reform on the African continent (Sagner 2000). It is estimated that a total $5 \%$ of the population of South Africa in 2006 is aged 65 and over (Population Reference Bureau 2006).

The older population will have to adapt to a changing society, which is particularly important for South Africa where the political changes had an influence on the dynamics of the society. This determined the status and position of the aged in society. Job opportunities in the cities caused a migration of young and 
middle-aged people, leaving the aged behind. In Africa the quality of life has not improved due to the psychosocial stress resulting from economic hardships for the whole continent (Mwabu 1998).

An ethnographic approach was chosen to obtain an understanding of the context of the daily life of elderly African persons. The co-operation involving researchers from South Africa and Sweden gave an opportunity to view the content from different angles. The aim of this paper is to identify and describe daily life and related concerns and interests as expressed by a group of elderly.

This study was performed by a team of South African and Swedish caring science researchers from the University of Pretoria and the Blekinge Institute of Technology/Karolinska Institutet which forms a part of a bilateral cooperation project in education and research between the institutions involved.

\section{Materials and Methods}

\section{Study design}

The focused ethnography approach was chosen and data were gathered during a specific time period (2001-2003), see Table 1.

Table 1 Preparation and Data Collection

\begin{tabular}{|l|l||}
\hline $\begin{array}{l}\text { Time Period } \\
2000\end{array}$ & Data \\
\hline \hline May 2000 & $\begin{array}{l}\text { Information meeting in the Majaneng area (at a clinic) with members of the family of the tribal chief and } \\
\text { community leaders as well as elderly from the community (approx. } 30 \text { participants). Several visits in the area. }\end{array}$ \\
\hline February 2001 & Follow-up meeting at the clinic. Volunteers were invited (approx. 25 participants). \\
\hline October 2001 & $\begin{array}{l}\text { Second follow-up meeting at the clinic where the same volunteers were invited and participants selected, see } \\
\text { criteria. }\end{array}$ \\
\hline October 2001 & Written reminder and personal visits to selected 12 participants: ten females/two males \\
\hline October 2001 & $\begin{array}{l}\text { Group interviews with five females and one male participant per group at university campus. Home visits to } \\
\text { participants. }\end{array}$ \\
\hline May 2002 & Home visits to participants and meeting at university campus. Presentation of preliminary findings. \\
\hline October 2003 & Male volunteers invited and participants (four) selected by contact person from the area. \\
\hline October 2003 & Additional group interviews with four male participants at university campus. \\
\hline
\end{tabular}

Muecke (1994) refers to these types of ethnographic studies as problem-oriented, involving a limited number of participants who usually are persons with a store of knowledge and insight relative to the phenomenon of study. As the study has an inductive, qualitative approach with different types of data collection and analysis methods, and as the aim is not to generalize and quantify, the limited number of participants was necessary to be able to handle the data in an appropriate way.

\section{Field site}

Selection of the site for research was done by visiting and evaluating the suitability of various areas in provinces of Mpumalanga and Gauteng in South Africa. Majaneng area, Hammanskraal district, was selected because of the geographical location and the relationship the Faculty of Health Sciences of the University of Pretoria has with the community of Majaneng. 
Majaneng is situated approximately $50 \mathrm{~km}$ north of Pretoria at Hammanskraal, a large district of villages, a township, informal settlements and farms with an estimated population of 300,000 (Census 2001, http://www.statssa.gov.za/census01/html/default.asp.), not including informal settlements. Majaneng is very densely populated, comprising a large number of blocks, with a mixture of formal and informal settlements, occupied by South African citizens and illegal immigrants from neighbouring countries. The area is made up of several sections and the district is under the leadership of a Traditional Authority with its office in Majaneng. From a local government perspective the district was under the Eastern District Council, North West Province, and since 6 December 2000 it has been under the city of Tshwane (Pretoria) Metropolitan Municipality. The entire area is about $5 \mathrm{~km}$ in radius and had been underdeveloped for ages until the ANC government took over in 1994. Under the former government, Majaneng was part of a Trust Land in the Bophuthatswana homeland.

Much of the public infrastructure, such as schools and churches, was built by the communities themselves. The road network is not streamlined and is in very bad shape. Since the closure of the railway line between Hammanskraal and Pretoria by the former Bophuthatswana homeland for safety reasons, access to train transportation has been denied to this community. The remaining transport that is at least affordable, although unreliable, is a bus service. Many of the homes consist of mud buildings and shacks.

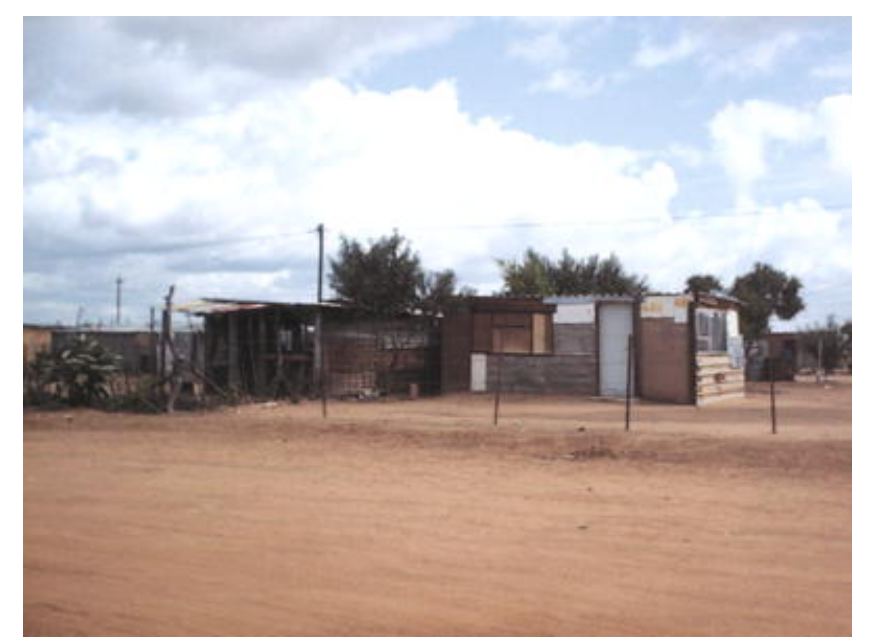

(c) Natie van Wyk 2002

\section{Gaining entry}

One of the research team members from South Africa connected to the University of Pretoria has regular contacts via clinics and as service deliverer to the Jubilee Hospital, which contributed to the development of a trusting relationship between the researchers and the research participants. In May 2000 an information meeting was set up with representatives of the Majaneng area, which involved the wife of the tribal chief and other senior members of the family of the tribal chief and community leaders at a clinic in Majaneng. At the meeting approximately 30 elderly from the community were present. The South African and Swedish research team conducted the meeting. The researchers used the opportunity to explain the proposed project and obtained the permission of the chief's wife to proceed with the research. The time spent with the community leaders at the onset of the research paid off in ongoing support from all the people involved. The original visit was followed up by a visit in February 2001, which involved approximately 25 elderly participants of the community. The purpose of this visit was to confirm participation in this project and to involve potential participants. 


\section{Participants}

A group of elderly people was chosen purposefully for their knowledge of the lifestyle of elderly people in the area of Majaneng. The criteria for participation in the study were: (a) the participants should be aged 55 and older; (b) equal numbers of women and men should be involved to obtain the female and male perspectives; (c) the participants had to have sufficient knowledge of English, as English was the language agreed upon for the interviews. The reason for the criteria of sufficient knowledge of English was the experience drawn by research team members, who had been involved in earlier community projects, that a majority of the elderly have a sufficient knowledge of English. Most people in Majaneng, situated fairly close to the urban area of Pretoria, have frequent contacts with English-speaking South Africans. The research team involved an interpreter (see below) to ensure that there would be no misunderstandings. In case of difficulties with language the interviews were transcribed by a person with knowledge of the local languages in the area.

In October 2001 volunteers were invited and 12 persons, ten females and two males, aged 58-76 years, agreed to take part in the study. Due to the difficulty in engaging male volunteers, the research group decided to involve a larger number of female participants. An interpreter participated during the interviews in case assistance were necessary. The participants were informed, the proposed research process was explained and the feasibility of their involvement was determined. After the first interviews the team discussed the necessity of involving more male participants to achieve a better balance on the female/male perspective. Therefore a group of four elderly men from the area, aged 55-71 years and with a sufficient knowledge of English, was engaged in October 2003. One of the participants, 52 years old, did not fulfil the age criterion of 55, but was involved in community activities including old people, and therefore his participation was valued.

Ethnicity has been taken into account in terms of the selection of Africans (blacks), which is the majority group of elderly represented in the Majaneng area.

The participants were invited to choose an appropriate meeting place. They agreed that the nearby satellite university campus was the most suitable venue for the group interviews. The participants were familiar with the campus through contacts with representatives from the University of Pretoria at the clinics in the area.

\section{Data collection}

Various data-gathering techniques were used, such as group interviews and home visits to the elderly with field observations. These observations included field notes and videotapes to get an overview of the daily activities that the participants were involved in.

\section{Group interviews}

Groups were used to facilitate the interview situation, as the participants had no previous experience of sharing personal experiences and beliefs connected to daily life and related concerns and interests in a research situation. Parahoo (1997) has shown that some people are more relaxed about expressing their opinions in a group than on their own, with an interviewer.

The elderly formed two groups according to their own choice. The only steering action was to have a male participant in each group. Two researchers (South African/Swedish) participated in each group. The interviews with four male participants were performed as a third group, which took place at a later stage with only one Swedish researcher. 
During the interviews tape recorders were used. English was the language agreed upon for the interviews; an interpreter participated during the first round of interviews, and thereafter assistance was not necessary as participants were comfortable with English as a foreign language.

To get a broader picture, the interviews covered topics focusing on daily life and related concerns and interests, see Table 2.

Table 2 Interview Guidelines

The participants reflected on the following topics related to activities of daily life:

Activities that happened yesterday

A normal week/weekend

Normal activities during the week/weekend

Enjoyments during the week/weekend

Other interests/concerns related to activities of daily living

The participating researchers managed the group interviews alternating between facilitation and taking additional notes to describe the interview situation. In total each participant took part in nine interviews lasting approximately one and a half hours each. In the additional interviews with the four male participants that took place at a later stage, each participant took part in three interviews. Each interview took place in sessions lasting approximately one hour. The group interviews were tape-recorded and transcribed verbatim and followed up by home visits to the participants.

\section{Home and community visits}

All researchers participated in individual home visits to those they had already met during the group interviews. This was done to get a better understanding of the living conditions of the elderly and their families. During the home visits, field notes were written, to describe the ways the elderly kept themselves busy every day and planned their daily activities. Video films were used as a complement to the field notes to support the description of the context.

In addition to group interviews and home visits, the researchers participated in community activities, for example, by taking part in a meeting with the tribal chief and by attending church ceremonies. At different times the researchers undertook trips to the area to observe the social and daily activities in which the people of Majaneng were engaged. The interaction between the researchers and the participants was not restricted to scheduled meetings for interviews but also involved personal contacts and discussions throughout the days of data collection.

\section{Data analysis}

A person with local knowledge of the community and proficiency in both English and the participants' first language transcribed the interviews. The material consisted of group interviews, videotapes and field notes.

The transcribed material was analysed using qualitative content analysis (Graneheim and Lundman 2004). The analysis was performed by one Swedish and one South African researcher independently. The analysis involved the following stages: the researchers reviewed the transcribed material independently by reading the transcripts and by repeatedly listening and viewing original data. Two sets of sub-themes, one from the Swedish side and one from the South African side, were compared and recurrent sub-themes were selected after discussion, resulting in one set of sub-themes. Once the subthemes were identified, the researchers shared the information with the participants in order to verify 
interpretations of the preliminary results. The results were presented and discussed through three group interviews involving the original participants (nine females and two males, as one female member had passed away). The additional interviews (with the four male participants) were analysed at a later stage to compare sub-themes from previous data and to determine whether new sub-themes had to be formulated. This also gave the researchers the opportunity to confirm the identified results. Finally, from the sub-themes, broader (analytical) themes emerged.

\section{Ethical considerations}

Approval from the Research Ethics Committees of South Africa (Faculty of Health Sciences Research Ethics Committee, University of Pretoria), Number S182/2001, and Swedish Authorities (Karolinska Institutet, Research Ethics Committee, Huddinge University Hospital), Number 2/02, was obtained. The literate participants gave written informed consent, while the illiterate participants verbally agreed to take part in the research after the researchers' explanation to them that the data would only be used for research purposes. The research group was aware of the vulnerability of the participants and the ethical considerations that had to be taken into account due to these circumstances.

\section{Results}

In answering how this group of elderly experience their daily life and related concerns and interests, the results are presented as identified sub-themes: Lack of basic resources; Routines in daily life; Experience of unsafe conditions; "The disease"-HIVIAIDS and emerging themes: Keeping normality and Changing society.

\section{Lack of basic resources}

Daily life is described as a constant lack of basic resources and a struggle to keep life as normal as possible. The context in which the participants live is characterized as an area with a variety of brick buildings and houses of mud or tin. A substantial section of the population lives in shacks. High poles with spotlights supply the area during the night with light and also serve as a mechanism to prevent crime. Every house has a number, and mail is delivered to post boxes spread over the area. Close to the area there are shops where the inhabitants can buy groceries. The infrastructure is fairly underdeveloped with tarred main roads and smaller dirt roads. Both the tarred and dirt roads are in bad condition. The standard of living within the group of participants is diverse; some live in brick houses with electricity and running water, while others have to cope with mud floors and without electricity and rely on communal taps. The latter are distributed over the area. Water has to be fetched in buckets and carried over three to four blocks to their homes. Those who do have electricity complain about its unreliability. They can be without electricity for several days and often without prior notice.

Let's say I go to the supermarket and buy meat and two kilo of mix portions of chicken. I bring them home and cook some, then put in the fridge. In the morning you may find that lights went off with no storm or anything. You will find that water is dripping from the fridge and things in the fridge become rotten and you will find that it takes the whole day without electricity and it will only come back at 21:00 at night. Sometimes lights go off for two days.

Many of the elderly share homes with children and grandchildren, but there are also those who have single households. To give a picture of the daily circumstances we have chosen to describe the home environment of one of the participants.

"N" lives in a house into which she moved during the '70s. She shares it with her grandchildren. The house is a rather big brick house with a yard surrounded with a wire fence. She has a small, well-kept 
lawn in front of the house; the rest of the yard is bare soil and tufts of grass. In the backyard she has a small garden with fruit-trees and vegetables such as cabbage, spinach, carrots, potatoes, corn and pumpkin. There is a water tap with cold water in the backyard where she washes the laundry and a small storehouse. The only lavatory is outside the house at the very end of the yard. It is a small building with a pit and made of corrugated iron. No sewerage service is provided to the area. The main house has one living room, a kitchen and two bedrooms. There are bars in front of all windows and doors. In the kitchen there is an electric stove, a refrigerator and cabinets where she keeps the pottery. There is also a tub with water for washing of dishes. Although "N" appreciates her kitchen, the refrigerator is broken and the stove can't be used, as she has no electricity. Instead she uses a paraffin stove to prepare meals. In her living room she has a set of furniture, carpets and a television set. As the television depends on electricity, it can't be used. In the room she keeps photographs of relatives and friends. The bedrooms are shared between her and her grandchildren.

The shortage of money is an overall concern of the participants. The only income is the old age pension, and they try in different ways to make the small resources last. Some sew pillows, and baskets and others use strips of plastic to knit small carpets to get an extra income.

But for the little material that we have, we try to make little things to sell them. I love to knit because I make money out of it.

Several people are financially responsible for up to three generations and use their pension for food support for the extended family. The constant lack of money and the very limited chances to get a job make them feel as if they are in a situation without hope.

But even if there can be water and electricity they need to be paid for...When coming to work, jobs are scarce, and it is the duty of the government to create jobs and employ the very same children without jobs although they are technically advanced.

They feel that if they do not support their children they will get involved in socially unacceptable activities and even crime. The participants have developed strategies to meet their daily difficulties and use equipment they had to rely on in the old days, such as paraffin stoves and candles.

\section{Routines in daily life}

The participants all have structured daily routines. They explain in detail all the different events during a day, and when the participants describe their daily life they all seem to have busy schedules. They do not seem to appreciate any changes in their routines. One participant illustrates her morning routine as follows. She gets up every morning at 05:00, except in winter. The routines include cleaning, cooking and organizing for the grandchildren.

I go to the kitchen, boil water and tidy the bed. I drink a cup of tea and go wash myself, then when I'm finished I start to clean the house... We are working and cleaning in our yards and our houses... Taking care of our grandchildren and every Tuesday we are sewing.

They enjoy gardening, and one participant explains how she goes straight to the garden and that she is always digging in the garden, even if there is a shortage of water. After a busy day, most participants spend their evenings watching television (if they have access to electricity or a battery-powered set) until they go to bed.

I make sure that at $17: 30$ I am home to prepare for supper. I wash my feet and watch TV till time to sleep. 
The daily routines during the weekends are described by one of the participants as cleaning their houses, preparing for weddings and going to funerals or going shopping. All different aspects of life are seen as part of daily life (birth to death).

Being active and having daily responsibilities gives structure to life and is defined as normal. Keeping themselves busy is according to them also a way of keeping themselves healthy. Several of the participants, however, have different health problems such as "high blood" and pain and say that the day you stay in bed you are dead.

One participant also points out the female perspective.

As women we do a lot, and we were taught that every morning when we wake up we must exercise to help ourselves... We are exercising to gain energy, to keep our body healthy and to gain strength.

The men articulate their interest in gardening and take responsibility for more physical work such as bringing water home as a way of being active and also as a contribution to the household. After a busy day they often feel very tired in the evening and sit and sleep on the couch before going to bed.

The family forms an important part of the daily routines. The participants continue to make decisions about their household and their family. Some have both children and grandchildren staying with them, where the grandmothers take the main responsibility for caring activities. One 72-year-old female participant explains how she prepared herself for our meeting; she had to wake up 05:30 to do her grandchildren's washing before she left home. Someone else explains how proud she was when her grandchild came and helped her. They enjoy being with their grandchildren, but as one participant put it, not all the time. They continue to feel responsible for the extended family, e.g., brothers, sisters or their children. Parenting is not the unique responsibility of the natural parents, due to several factors such as sickness or social insufficiency in the form of unemployment, drug/alcohol abuse and teenage pregnancies; instead it is an unspoken or explicit expectation that the elderly take care of the grandchildren.

We as old people look after these grandchildren, we cook for them, we do their washing, we do all sorts of things for these children.

One member of the group expressed it thus:

We always tell them that we can die anytime, so they must learn while we are still alive to take care of their children.

Many of the participants have a regular routine of visiting friends for tea or juice drinking and to exchange ideas. To meet friends, to show them you are there for them, is seen as very important to the participants. They rely on each other, and they help each other.

The use of cell phones has increased as it makes it possible for relatives and friends to reach them even if they cannot call themselves. They move around freely, although not in the evenings. Often the elderly have to rely on other elderly for their needs. One of the participants says:

I went to visit three of my friends. You know two of my friends have been ill, but yesterday I found one of them to be feeling much better and the other one isn't sick anymore.

Not everyone believes that family members will take care of them if they get sick.

I get sick my family would never come if I call them. 
Social activities with friends, according to the participants, include attending weddings and funerals, going to church, visiting friends and family. Socializing is about being among people under any circumstances. One of the participants describes how having a meal with friends is important and how African people share. Not being able to share resources, according to them, makes them feel bad, and as they explained it makes their hearts ache.

Community activities are also included in regular routines. Some of the participants are strongly committed to community activities outside the home as members of a care group and a sewing group. They describe a well-organized structure which the elderly have established themselves due to the shortage of public support, with an informal support system to assist those who are in need.

Our village is divided into sections and each section has a subcommittee that looks after the demands of the community or that particular section.

Most of the female participants take part in the sewing group several times a week, where they make pillows and baskets, which they sell and use income to support the elderly. One of the participants describes her weekly programme:

Mondays I'm busy at home and on Tuesday I do sewing and also on Wednesday I do sewing and also on Thursday I do sewing at home and the other days as well.

Meetings are also held at the chief's place once a month, where they discuss old age and how they can take care of themselves and the other elderly people in the community.

To share the little you have is fundamental for the participants. Many of them are involved in regular activities connected with the church, for example fund raising for people in need. There is a strong commitment among elderly in Majaneng to support each other, meaning both the participants themselves and other older people in the area. Church is a place where you meet your friends and where you make friends. It is also seen as a place where you extend your knowledge. As someone expresses it, in church we have been taught a lot and we have also been taught to teach the others what we are taught in church. They belong to different churches and contribute monthly to their congregation.

\section{Experience of unsafe conditions}

The participants are living in a period of ongoing changes, and they describe a daily life which to a large extent is influenced by the societal changes. Alcohol, drugs and concomitant crimes and violence are all factors related to their experience of unsafe conditions. The participants fear the weekends when people abuse alcohol and drugs and most crimes are committed. They say that night time is the chance for thugs to steal, because there is no electricity and they can't even phone the police. Even if some of them have cell phones they only use the phones to be reached, not to reach others, because of their lack of money.

They think that alcohol and drugs have a very severe impact on the young people and are a major cause of people acting cruelly and committing brutal assaults. Crime has become a part of daily life. One of the participants talks about the fear of being raped and refers to an old lady in the neighbourhood who was beaten and raped in her own home and left to die. Those who commit the crimes are in many cases, but unfortunately not always, strangers. They often talk about their fear even of people they know. Many of them have personal experiences of relatives who have been murdered.

My niece's son was one day shot when he was going to work in the morning and died.

Some also have relatives who have been involved in criminal activities and are in prison. 
Yes, things have changed; they are no longer the same. There is a lot of violence and people are killing us and killing each other. Before we used to be afraid of snakes and lightning, but today we are not safe in our own houses. People are cruel. I never go out in the evening.

As they express it, nowadays things are no longer safe as before, and the young generation have no respect for them as elderly.

You find that young people look for green pastures more or less... You know, old as I am, my mother and father, if they were still alive, I'm still their son. You don't find that type of great respect.

According to them, people are not afraid of coming into one's yard to kill whether the yard is lighted or not. The toilets are outside and they have to make use of chamber pots at night as they are too frightened of going out of their homes after sunset.

They are especially concerned when they have to pick up the old age pension at "pay points" where they are very vulnerable. They believe that an improvement in the security and police networks will prevent many crimes in their community.

\section{"The disease"-HIVIAIDS}

The impact of the HIVIAIDS epidemic on daily life in the community is significant. The participants prefer not to call HIVIAIDS by name; instead they refer to "the disease". Many of them express their concern over young children dying of HIVIAIDS. They speak about their children who are dying of AIDS and complain that the children do not want to listen to them about how to avoid the disease. One of the participants says they have to "bring their heads together" as parents on what they can do to stop this illness from killing their children. They are concerned about the young people who do not respect their bodies and explain that they were taught to respect their bodies. They react to the circumstances that young people are exposed and encouraged to use contraceptives, which they see as an approval of an early sex debut.

You will find boxes, and people working with it they give them to kids. You may find that these kids are playing about them. Those boxes contain condoms, and they are being given freely.

At the same time, they express their concern about young people getting "the disease". They experience a new funeral every weekend and are deeply frustrated as parents to see many of the young dying of the disease. They also fear the day when they will pass away and what will happen to their children and grandchildren.

We may die at any time, and it worries us to see our kids dying of this epidemic.

They say that no one is strong alone, and to achieve change you need to co-operate and tell the government that this must start at grass-roots level. They feel that even if they have contributions to make they have no way of getting them through to the authorities.

We don't have a community centre where people could be called to talk... When we have to meet as a community we meet in an open space and few people will attend.

The data and identified sub-themes were reread and two themes emerged: keeping normality and changing society. 


\section{Keeping normality}

The participants' daily life is built up of a range of routines, strategies involving activities to compensate for the lack of basic resources and counteract the unsafe conditions in order to keep life as normal as possible. Their days are fully booked with activities trying to keep their households together. The old age pension is regarded as the main financial factor to sustain a sense of normality in daily life. They also describe an informal support network of friends and family as one strategy to compensate for the lack of formal support. Their strategies are redefined in accordance with changes in their daily life. They also connect being active to maintaining health and view passivity as the first step to illness.

\section{Changing society}

The participants express their fears for the future; the past is seen as a "safe" period, and they feel that people have changed during the past couple of years. They are concerned about the unsafe conditions and the influences of this on their lives. They say that things have changed and you are a part of it, and that people of today have a different reality. They feel frustrated facing the consequences of the HIVIAIDS epidemic and they are worried about their own care, especially in very old age, and their response to the question of who is going to take care of them is: "Nobody or my children". When they grew up they were one big family and no one was isolated, but today everyone is for themselves because things are different now. They are expected to be responsible for all the young children in their homes until they can no longer continue. The participants say they are not happy looking after their grandchildren all the time and that it is time for their mothers to look after them.

\section{Discussion}

The main results from this study identified and described the daily life and related concerns and interests of the participants in terms of: lack of basic resources; routines in daily life; experience of unsafe conditions; "the disease"-HIVIAIDS. The results are discussed focusing on the themes that emerged: Keeping normality and Changing society.

The results of the study reveal the daily life of a group of elderly African people characterized by a need to maintain normality by continuing with their daily life in a way that they consider as acceptable and thus normal. It involves staying physically active and keeping to a range of routines despite a constant lack of basic resources. Their daily life is also characterized by involvement in caring for family and friends and with a strong community commitment. The study furthermore shows the participants' experiences of unsafe conditions and a growing impact of "the disease" (HIVIAIDS epidemic) in a changing society. Even if they might have been equally unsafe under apartheid, nevertheless the opinion of the elderly is that, when it comes to their own personal security, they were safer in the past, the police were present, the drug traffic was not at least so open and there were more job opportunities.

According to United Nations Population Fund (2002), the essential issue connected to ageing populations in developing countries is lack of resources, poverty. The South African Human Development Report (SAHD; 2003) estimates that approximately $50 \%$ of South Africa's population falls below the national poverty line. Africans constitute the majority of the poor in the country and are also the main beneficiaries of the current old-age pension programme, which frequently provides the only income for support of the extended family (Moller and Sotshongaye 1996; Moller 1998; Reddy 2002). Our study reveals a situation where many of the elderly are the only ones with a regular income, having to support the rest of the family on a monthly pension. According to Wilson and Ramphele (1989) and Narayan (2000), poverty consists of many interlocking dimensions. It is rarely about the lack of only one thing; the bottom line is always hunger-the lack of food-but it has also important psychological dimensions, such as powerlessness and dependency. Narayan (2000) points out that poor people lack 
access to basic infrastructure-roads, transportation, and clean water, which is in line with the results of this study.

If lack of basic resources for this group of people can be seen as a prolonged "normal" situation, with its roots in historical policies (Heslop et al. 2000), the additional circumstances, such as escalating crime incidents, the fear of an insecure future for children and grandchildren and the adaptation to a more "modern," westernized society are seen as an ongoing transitional process.

While acknowledging some societal changes as having had a positive effect on their lives, at the same time they are concerned about their loss of cultural norms. They are frustrated because they view the transition from "old times" to "modern times" as a loss of values and the greatest threat to the family traditions, and they verbalize the fear of being without care, as family support can no longer be taken for granted.

The effects of "the disease" (HIVIAIDS epidemic) in the community have also put extra pressure on the elderly in terms of caring for children and grandchildren, described as the grandmother's disease of Africa in the South African Policy for Older Persons (Department of Social Development 2002). Much of the childcare is provided by the grandparents, so instead of being cared for, they are supplying the care (Leete and Jacobs 2002). The gender issue cannot be ignored, and in accordance with previous studies the female participants have the main responsibility for caring (HelpAge International/International HIVIAIDS Alliance 2003; Oppong 2006). They also say that they do not feel safe in their own homes, and sometimes not even with their own relatives. Financial abuse is shown to be common against elderly people because of the situation with the old age pension as the only income, and the abuse also takes the form of children expecting older persons to care for grandchildren and perform housework without being paid (Reddy 2002). Apt (1996) argues that keeping themselves busy and involved in family matters is a way for the elderly in developing countries to preserve their social and self-esteem and maintain their active status, reducing the risk of social abandonment, but clearly these elderly Africans are so busy they feel over-involved and even exploited by their families.

Activities of daily life mirror a South Africa in a transitional period, where the transition, referring to the theoretical framework developed by Schumacher and Meleis (1994), involves developmental, situational and organizational changes, as well as changes in health and illness. All these changes have a multidimensional and complex effect on identities, roles, relationships, abilities and patterns of behaviour at the individual and family level, and on structure, function and dynamics at the societal level (Meleis et al. 2000; Schumacher and Meleis 1994).

Emerging themes such as changing society and keeping normality can be explained in terms of the characteristics of this transition framework (Meleis et al. 2000), including complex parallel processes on both a societal (macro) and a personal (micro) level, as structural changes in the society and individual experiences in terms of impact on daily life. Feelings of insecurity, loss of values and the individual interpretation of meanings reflect the individual processes, and developed and reshaped strategies to meet the ongoing changes can be seen in a wider socio-cultural context.

\section{Methodological considerations}

The qualitative ethnographic approach was chosen to grasp the individual experiences of the participants and does not aspire to be a comprehensive account of the situation of the elderly in Majaneng. Eliciting experiences of daily life and related concerns and interests of a group of elderly may nevertheless give an opportunity to show some general features experienced by elderly living in similar circumstances. The fact that the researchers involved have different pre-understandings also has to be considered in the analysis process. Initially dividing the first part of the analysis process was a way to ensure that both perspectives were taken into account, and it also gave the opportunity to broaden the 
perspective and to validate the results. The interpretations of the preliminary results were also verified through follow-up meetings with the participants. The approach to "daily life and related concerns and interests" has its limitations but is essential for the understanding of the context in forthcoming articles.

\section{Conclusion}

The results of the study partly confirm previous knowledge related to living conditions for elderly South Africans. However, this study illuminates the varied experiences in daily life, including lack of basic resources, experience of unsafe conditions, as well as the HIVIAIDS pandemic, and its consequences for the elderly as contributors to the extended family.

Modernization, economic and social transformation have undermined traditional structures and practices, which have increasingly obliged governments to offer alternative support systems. Although promising initiatives have been taken, a lot still has to be done to achieve the objectives.

This study supplies knowledge about a vulnerable group in a time of transition and paints a portrait of a group of elderly who contribute to their families as well as to the community and where the grandmothers play a significant role as caregivers.

Acknowledgements The research and work on this manuscript was supported by grants from the Nordic Africa Institute, Uppsala, Sweden. The authors gratefully acknowledge the assistance of Dorricha Peu, lecturer at the University of Pretoria, and of Alan Crozier for revising the English.

\section{References}

Apt, N. A. (1996). Coping with old age in a changing Africa. Avebury: Aldershot.

Department of Social Development (2002). South African Policy for Older Persons (sixth draft). Pretoria: Department of Social Development.

Department of Social Development (2003). The Older Persons Bill. Pretoria, Republic of South Africa: Department of Social Development.

Flessa, S. (2000). Where efficiency saves lives: A linear programme for the optimal allocation of health care resources in developing countries. Health Care Management Science, 3(3), 249-267.

Graneheim, U. H., \& Lundman, B. (2004). Qualitative content analysis in nursing research: Concepts, procedures and measures to achieve trustworthiness. Nurse Education Today, 24(2), 105-112.

HelpAge International/International HIVIAIDS Alliance (2003). Forgotten families, older people as carers of orphans and vulnerable children. Policy Report. Retrieved from http://www.helpage.org/publications/publications.html.

Heslop, A., Agyarko, R., Adjetey-Sorsey, E., \& Mapetla, T. (2000). The contribution of older people to society: Evaluation of participatory research methodology employed in studies in Ghana and South Africa. Southern African Journal of Gerontology, $9(2), 6-12$.

Leete, R., \& Jacobs, T. (2002). The older poor and excluded in the developing world. In Situation and voices: The older poor and excluded in South Africa and India. Population and development strategies series (No. 2, pp. 1-15). New York: UNFPA.

Meleis, A. I., Sawyer, L. M., Im, E.-O., Hilfinger Messias, D. K., \& Schumacher, K. (2000). Experiencing transitions: An emerging middle-range theory. Advances in Nursing Science, 23(1), 12-28.

Moller, V. (1998) The pension "crisis" in the Eastern Cape Province. Southern African Journal of Gerontology, 7(1), 32-35. 
Moller, V., \& Sotshongaye, A. (1996). "My family eat this money too": Pension sharing and self-respect among Zulu grandmothers. Southern African Journal of Gerontology, 5(2), 9-19.

Muecke, M. A. (1994). On the evaluation of ethnographies. In J. M. Morse (Ed.), Qualitative nursing research: A contemporary dialogue (pp. 187-209). Newbury Park, California: Sage.

Mwabu, G. (1998). Health development in Africa. Economic Research Papers No 38. African Development Bank.

Narayan, D. (2000). Voices of the poor, can anyone hear us? New York: Oxford University Press.

OECD (2003). DAC list of aid recipients. Retrieved from http://www.oecd.org/dac/stats/daclist (1 January 2003).

Oppong, C. (2006). Familial roles and social transformations, older men and women in Sub-Saharan Africa. Research on Aging, 28(6), 654-668.

Parahoo, K. (1997). Nursing research: Principles, process and issues. London: Macmillan.

Population Reference Bureau (2006). 2006 World population data sheet. Washington, DC: Population Reference Bureau.

Reddy, P. (2002). The plight of older persons in South Africa. In Situation and voices: The older poor and excluded in South Africa and India. Population and development strategies series (No. 2, pp. 19-58). New York: UNFPA.

Sagner, A. (2000). Ageing and social policy in South Africa: Historical perspectives with particular reference to the Eastern Cape. Journal of Southern African Studies, 26(3), 523-553.

Schumacher, K. L., \& Meleis, A. I. (1994). Transitions: A central concept of nursing. Journal of Nursing Scholarship, 26(2), 119127.

South African Human Development Report (2003). The challenge of sustainable development in South Africa: Unlocking people's creativity. Oxford, UK: United Nations Development Programme (UNDP), Oxford University Press.

Statistics South Africa (2004). Consolidated expenditure by the general government sector, 2002/2003, Statistical release P9119. Pretoria: Statistics South Africa.

United Nations Population Fund (2002). Population ageing and development operational challenges in developing countries. Population and Development Strategies Series (No. 5). New York: UNFPA.

US Census Bureau (2004). International population reports WP/02, global population profile: 2002. Washington, DC: US Government Printing Office.

Wilson, F., \& Ramphele, M. (1989). Uprooting poverty—The South African challenge. Claremont: David Philip. 